\title{
Endoscopic Findings in Patients Under the Age of 40 Years with Hematochezia in Singapore
}

\author{
Man Hon Tang, Fung Joon Foo and Chee Yung Ng \\ Department of Colorectal Surgery, Singapore General Hospital, Singapore
}

Background/Aims: Sigmoidoscopy is performed in most medical centers to evaluate the distal colons of young adults presenting with hematochezia who are at risk of developing proximal lesions. Colonoscopies offer more complete evaluations but are associated with a higher incidence of complications and possible low yield.

Methods: An analysis was conducted on colonoscopies performed in our center on patients 40 years of age or younger. The study population was sub-divided into 2 age groups for analysis: $<30$ years of age and 30-39 years of age.

Results: We recruited 453 patients for the study. Patients were 115 and 338 individuals that were $<30$ and $30-39$ years of age, respectively. Hemorrhoids was identified as the cause of bleeding in the majority of cases. The overall incidence of polyps was $6.5 \%$; this was significantly higher in the $30-39$ age group ( $7.4 \%$ vs. $1.7 \%, p=0.026)$. There were two cases of advanced/malignant polyps. While the majority of the polyps were in the distal colon, $28 \%$ of the polyps in the older age group were found in the proximal colon. There was one case of colonic perforation.

Conclusions: Colonic polyps are more prevalent in patients aged 30-39. Colonoscopies should be considered for patients over the age of 30 with rectal bleeding. Clin Endosc 2020;53:466-470

Key Words: Colonic neoplasm; Colonoscopy; Gastrointestinal hemorrhage

\section{INTRODUCTION}

Per-rectal bleeding is a common complaint in young adults presenting to outpatient clinics. Studies have shown that up to $20 \%$ of the population have noticed bleeding per rectum and that it is more common in those between 20-40 years of age; however, only a small fraction of these individuals have seen a physician. ${ }^{1-3}$ While benign anorectal conditions account for the vast majority of per rectal bleeding, many patients also have concomitant lesions within the colon.

The primary function of a colonoscopy is to exclude the

Received: January 12, 2020 Revised: February 2, 2020

Accepted: March 11, 2020

Correspondence: Man Hon Tang

Department of Colorectal Surgery, Singapore General Hospital, Outram Road, Singapore 169608, Singapore

Tel: +65-9673-5362, Fax: +65-6227-3787, E-mail: manhon_86@hotmail.com ORCID: https://orcid.org/0000-0003-2762-5580

(c) This is an Open Access article distributed under the terms of the Creative Commons Attribution Non-Commercial License (http://creativecommons.org/ licenses/by-nc/3.0) which permits unrestricted non-commercial use, distribution, and reproduction in any medium, provided the original work is properly cited. possibility of underlying colonic malignancy. There is also increasing evidence to suggest that rates of neoplastic lesions in younger patients are as high as $9.9 \%-17.9 \%$, especially in those aged 40-50 years, for whom colonoscopies are highly recommended. ${ }^{4-6}$ However, the utility of colonoscopies is believed to be very low, especially for patients younger than 40 years of age. Additionally, there remains no clear guideline or cutoff age with respect to the need for colonoscopic evaluation, for this younger group of patients with rectal bleeding. There are few, limited studies in the literature, and most of them have small sample sizes. Controversy remains regarding whether a full colonoscopy is necessary or if a sigmoidoscopy will suffice for young patients with rectal bleeding.

A total of 6 relevant articles on colonoscopy in young patients with rectal bleeding were included, based on a literature search. ${ }^{6-11}$ Data regarding colonoscopic findings in patients younger than 40 years old were extracted and are summarized in Table 1, below. The study by Carlo et al. assessing patients below the age of 45 , was also included. ${ }^{8}$ The studies' publication dates range from 1994-2011. The study with the largest cohort size of 314 patients was Lewis et al. ${ }^{6}$ The incidence of 
Table 1. Summary and Recommendations from Literature Search Results

\begin{tabular}{|c|c|c|c|c|c|c|}
\hline \multirow{2}{*}{ Study } & \multicolumn{2}{|c|}{ No. of patients } & \multirow{2}{*}{$\begin{array}{c}\text { Adenoma } \\
(\%)\end{array}$} & \multirow{2}{*}{$\begin{array}{c}\text { Advanced } \\
\text { adenoma (\%) }\end{array}$} & \multirow{2}{*}{$\begin{array}{c}\text { Carcinoma } \\
(\%)\end{array}$} & \multirow{2}{*}{$\begin{array}{c}\text { Recommended } \\
\text { evaluation }\end{array}$} \\
\hline & Age $<30$ & Age $30-40$ & & & & \\
\hline Acosta et al. $(1994)^{9}$ & 280 & & $25(8.9)$ & 0 & $1(0.03)$ & Colonoscopy \\
\hline Lewis et al. $(2001)^{6}$ & 133 & 181 & $9(2.9)$ & 1 & 0 & Sigmoidoscopy \\
\hline Carlo et al. $(2006)^{8}$ & $180^{\text {a) }}$ & & $2(1.1)$ & 0 & 0 & Sigmoidoscopy \\
\hline Spinzi et al. $(2007)^{10}$ & N/A & 312 & $14(4.5)$ & $7(2.2)$ & $2(0.6)$ & Sigmoidoscopy \\
\hline Nikpour et al. $(2008)^{7}$ & 177 & & $8(4.5)$ & 0 & $4(2.3)$ & Sigmoidoscopy \\
\hline Khalid et al. $(2011)^{11}$ & 248 & & $3(1.2)$ & 0 & $4(1.6)$ & Sigmoidoscopy \\
\hline
\end{tabular}

N/A, not available.

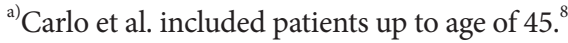

polyps ranged from $1.1 \%-8.9 \%$ while the incidence of carcinoma remained very low in this group of patients. Most of the studies concluded that sigmoidoscopy is sufficient for evaluating rectal bleeding in young adults. This conclusion took into consideration the risks and cost of the extensive workup involved, and that most of the lesions are located distally. Only Acosta et al. recommended a complete colonoscopic evaluation due to the significant rates of colonic polyps in their study. ${ }^{9}$

Due to the increasing incidence of young patients being newly diagnosed with colorectal cancer, we believe there is a possibility that colonoscopies should be considered for symptomatic patients, aged 40 and above. We aim to evaluate the necessity of colonoscopies for patients aged 40 or younger, with rectal bleeding, through a retrospective study of our own institution's results from patients belonging to this cohort.

\section{MATERIALS AND METHODS}

A literature search was performed of PubMed using the keywords "colonoscopy", "colonoscopic", "young", "bleeding", and "hematochezia". References from relevant articles were also included in the literature search. Both retrospective and prospective studies, involving colonoscopic evaluations of patients aged 40 years or less with rectal bleeding, were included. Relevant studies were included if they contained clear documentation of patients' ages ( $<40$ years old), colonoscopy findings, and histopathology. Only articles written in English were considered.

A retrospective analysis was performed of all colonoscopies performed in Department of Colorectal Surgery, Singapore General Hospital. Patients were included in this study only if rectal bleeding was the sole indication for colonoscopy. Patients with other concomitant symptoms such as changes in bowel habits, positive occult blood, pain, loss of weight, and anemia were excluded. Those who had previous colonoscopies or imaging, a personal or family history of colorectal cancer, known or suspected Lynch syndrome or familial adenomatous polyposis (FAP), and raised oncological makers were excluded from this retrospective study. No attempt was made to characterize rectal bleeding (i.e., color, mixed with feces) as doing so appears to have little diagnostic value.

Patient data were retrieved from the retrospectively collected electronic database for all patients under the age of 40 that had a complete colonoscopy performed in the 2-year period from January 2013-December 2014. All colonoscopies were performed or supervised by senior accredited clinicians. Data collected included patient demographics and history, indications for colonoscopy, colonoscopy findings, as well as all histopathological reports. Colonic lesions were classified according to location: proximal to the splenic flexure or distal to (and including) the splenic flexure. The study population was further subdivided into two age groups: $<30$ years of age and 30-39 years of age. Approval from the institutional review board was waived for this retrospective review.

For statistical analyses, chi-squared tests were performed for all categorical variables, using the Statistical Package for the Social Sciences (IBM SPSS Statistics version 20.0; IBM Co., Armonk, NY, USA). Results with a $p$-value $<0.05$ were considered statistically significant.

\section{RESULTS}

A total of 16,933 colonoscopies were completed within this time interval by our department, of which 1,150 were performed on patients under the age of 40 . Based on the exclusion criteria above, 696 patients were excluded. The remaining 453 
Table 2. Study Population Demographics and Colonic Polyps within the Two Age Groups

\begin{tabular}{|c|c|c|c|c|}
\hline & $\begin{array}{c}\text { Total } \\
(n=494)\end{array}$ & $\begin{array}{l}\text { Age }<30 \\
(n=115)\end{array}$ & $\begin{array}{c}\text { Age } 30-39 \\
(n=379)\end{array}$ & $p$-value \\
\hline No. Male (\%) & $302(61.1 \%)$ & $55(47.8 \%)$ & $247(65.2 \%)$ & 0.03 \\
\hline Median age & 32 & 26 & 35 & - \\
\hline Patients with polyps & $63(12.7 \%)$ & $6(5.2 \%)$ & $57(15.0 \%)$ & 0.06 \\
\hline \multicolumn{5}{|l|}{ Ethnicity } \\
\hline Chinese & $426(86.2 \%)$ & $103(89.5 \%)$ & $323(85.2 \%)$ & \multirow{4}{*}{0.43} \\
\hline Malay & $36(7.3 \%)$ & $7(6.1 \%)$ & $29(7.7 \%)$ & \\
\hline Indian & $27(5.5 \%)$ & $5(4.3 \%)$ & $22(5.8 \%)$ & \\
\hline Others & $5(1 \%)$ & $0(0 \%)$ & $5(1.3 \%)$ & \\
\hline No. of colonic polyps & 67 & 6 & 61 & - \\
\hline Hyperplastic & 35 & 4 & 31 & \multirow{4}{*}{0.026} \\
\hline Adenoma & $30(6.1 \%)$ & $2(1.7 \%)$ & $28(7.4 \%)$ & \\
\hline Advanced adenoma & 1 & 0 & 1 & \\
\hline Carcinoma & 1 & 0 & 1 & \\
\hline
\end{tabular}

patients included in the study were further subdivided into 2 groups: those aged $<30$ years ( 115 patients) and those aged 30-39 years (338 patients). The majority of those who underwent a colonoscopy were male (61.1\%; Table 2$)$, and the older group was significantly larger than the younger group. There are no differences in ethnicity between the 2 age groups.

Across 63 (12.7\%) patients, 67 colonic polyps were detected. Four patients had 2 polyps detected. Histopathology showed that polyps were hyperplastic polyps $(n=35)$ and tubuloadenomas with low grade dysplasia $(n=30)$. One case each of advanced adenoma and carcinoma were detected in the distal colons of patients in the 30-39 age group. The adenomatous polyp was a $12 \mathrm{~mm}$ pedunculated polyp. Histology showed the polyp to be adenoma with high grade dysplasia and no underlying malignancy. The malignant polyp was a $15 \mathrm{~mm}$ sessile polyp with histology showing high grade dysplasia with a focus of adenocarcinoma. The remaining adenomas were less than $10 \mathrm{~mm}$ in size with no high-risk characteristics.

Excluding hyperplastic polyps, the overall incidence of significant polyps was $6.5 \%$, with a significantly higher incidence in the 30-39 age group as compared to the $<30$ age group (7.4\% vs. $1.7 \%, p=0.026)$. While the majority of polyps were detected in the distal colon, $28 \%$ of patients in the 30-39 age group had proximal polyps (Table 3 ). The two patients with polyps in the $<30$ age group had distal polyps. The older age group was also more likely to have adenomatous polyps than hyperplastic polyps. Hemorrhoids were present in almost all patients. Other colonoscopic findings included non-specific colitis, diverticulosis, and anal fissures (Table 4).
There was one case of colonoscopic-related complications, in which a 26-year-old gentleman with rectal bleeding had a colonoscopy and polypectomy which showed a polyp of the descending colon. He presented one day later with acute abdominal pain, and a scan showed a colonic perforation. He subsequently underwent a laparoscopic primary repair of the perforation site and was discharged in good health.

Table 3. Location of Colonic Adenoma and Malignant Polyps

\begin{tabular}{lcc}
\hline Location of polyps & Age $<30$ & Age 30-39 \\
\hline Proximal & $0(0 \%)$ & $8(26.7 \%)$ \\
Distal & $2(100 \%)$ & $22(73.3 \%)$ \\
Total & 2 & 30 \\
\hline
\end{tabular}

Table 4. Colonoscopy Findings in Young Patients with Rectal Bleeding

\begin{tabular}{lccc} 
Lesions & $\begin{array}{c}\text { Total } \\
(\boldsymbol{n}=\mathbf{4 9 4})\end{array}$ & $\begin{array}{c}\text { Age }<30 \\
(\boldsymbol{n}=\mathbf{1 1 5})\end{array}$ & $\begin{array}{c}\text { Age 30-39 } \\
(\boldsymbol{n}=\mathbf{3 7 9})\end{array}$ \\
\hline Colitis, NOS & $18(3.6 \%)$ & 4 & 14 \\
Diverticula & $12(2.4 \%)$ & 2 & 10 \\
Fissures & $6(1.2 \%)$ & 3 & 3 \\
Angiodysplasia & $2(0.4 \%)$ & 0 & 2 \\
Inflammatory bowel disease & $2(0.4 \%)$ & 0 & 2 \\
\hline Rectal ulcer & $2(0.4 \%)$ & 0 & 2 \\
\hline
\end{tabular}

NOS, non other specific. 


\section{DISCUSSION}

Many young patients present to outpatient clinics with complaints of rectal bleeding, which is often diagnosed as hemorrhoidal bleeding. ${ }^{12}$ While this diagnosis is correct for most patients, there have been increasing rates of colorectal cancer detected in young patients, with many of these cases being sporadic and in patients with no family history of the disease. ${ }^{13}$ There are currently no clear guidelines regarding the management of young adults presenting with rectal bleeding. Patients' descriptions of the character of rectal bleeding have little diagnostic value in deciding which patients require colonoscopies rather than flexible sigmoidoscopies. ${ }^{14}$

The incidence of colorectal cancer, locally in Singapore, has been rising and is currently the most common cancer diagnosis in males and the 2nd most common in females. Although the incidence of colorectal cancer increases drastically after the age of 50 , the incidence in young patients remains significant at about 30 cases per 100,000 in those aged $<50$ years. Survival rates have also generally improved with advances in surgical techniques, chemotherapy and radiotherapy, as well as with earlier detection, attributable to screening programs and colonic evaluations. ${ }^{15}$ In Singapore, those aged $>50$, who are at an average level of risk, are encouraged to get fecal occult blood tests to screen for colorectal cancer. Those with positive fecal occult blood tests or those at increased risk of developing colorectal cancer are advised to undergo a colonoscopy. ${ }^{16}$

Traditionally, it has been thought that a sigmoidoscopy is sufficient to evaluate the distal colon in young patients, as most colonic pathology arises distally. Previous studies have also concluded that colonoscopies are unnecessary due to their relatively low rates of detection for colonic polyps. However, with the easy access to tertiary services in developed countries, some centers, including our own, now offer colonoscopies even to younger patients with rectal bleeding. Moreover, we have shown in our study that even with the exclusion of patients with a family history of colonic polyps, the rates of occurrence are still noteworthy in young patients with no family history. This is especially the case in those aged 30 years or older. Also, the current study showed that approximately a quarter of polyps are proximally located. However, there is no evidence to suggest that the practice of performing complete colonoscopies for young age groups, with the aim of detecting colonic polyps or malignancy, has any survival benefits over performing flexible sigmoidoscopies. The results of this study can be used as reference for treating patients who present with hematochezia. While a sigmoidoscopy is sufficient to evaluate the cause of the bleeding, patients should be aware of the incidence of incidental polyps noted during endoscopic evaluation and an upfront colonoscopy should also be discussed.

We acknowledge that these colonic polyps are incidental findings and not likely the cause of rectal bleeding. While the primary aim of colonic evaluation is to exclude malignancy, adenomatous polyps-an established precursor to malignancy-are also commonly detected and removed due to colonic evaluation. Young adults, in whom colonic adenomatous polyps are detected, have an increased risk of developing colorectal carcinoma later in life, and they usually present subsequently with a more advanced-stage disease and a poorer survival rate. ${ }^{17}$ As such, the detection and recognition of colorectal cancer in its premalignant stage is crucial. Colorectal cancer under the age of 30 is a rare entity, especially when there is no family history or a pre-existing genetic predisposition, such as FAP or Lynch syndrome. Colonic polyps are also very uncommon at such a young age. Although the risk of significant complications arising from colonoscopies, such as colonic perforation, remains very low in high-volumes centers, the risk should still be balanced against the low yield.

The proportion of males was significantly higher in the older age group. While the authors could not identify any particular reason to explain this difference, we acknowledge this could result in some bias in this study. A meta-analysis found that male are at higher risk for developing advanced colorectal neoplasia across all age groups. ${ }^{18}$ In the Asian population, the rates of inflammatory bowel disease are low compared to the West. In this study, we have excluded patients that had other symptoms such as abdominal discomfort or loss in weight. However, the diagnosis of inflammatory bowel disease should be considered in patients with rectal bleeding and other concomitant symptoms. A full colonoscopy should be performed, regardless of age, especially to detect possible proximal lesions in Crohn's disease.

Overall, the risk of malignancy in young patients with no family history remains very low. We found that the incidence of colonic polyps within our younger population is significant, and that this incidence increases with age. Also, up to a third of these polyps were detected in the proximal colon in the 30-39 years of age group. Although the majority of these colonic polyps were benign, early detection and polyp removal is equally important in this group of patients, as these polyps can become malignant in future if they are not removed.

The older age group (30-39 years of age) is also more likely to have adenomatous polyps that warrant polypectomy. While there is currently no strong evidence for colonic screening below the age of 50, we recommend that the option of a colonoscopy should be discussed with patients even though a flexible sigmoidoscopy is sufficient to evaluate hematochezia. 
Conflicts of Interest

The authors have no financial conflicts of interest.

ORCID

Fung Joon Foo: https://orcid.org/0000-0002-7347-4894

Chee Yung Ng: https://orcid.org/0000-0002-9839-4110

\section{REFERENCES}

1. Dent OF, Goulston KJ, Zubrzycki J, Chapuis PH. Bowel symptoms in an apparently well population. Dis Colon Rectum 1986;29:243-247.

2. Fijten GH, Blijham GH, Knottnerus JA. Occurrence and clinical significance of overt blood loss per rectum in the general population and in medical practice. Br J Gen Pract 1994;44:320-325.

3. Talley NJ, Jones M. Self-reported rectal bleeding in a United States community: prevalence, risk factors, and health care seeking. Am J Gastroenterol 1998;93:2179-2183.

4. Wong RF, Khosla R, Moore JH, Kuwada SK. Consider colonoscopy for young patients with hematochezia. J Fam Pract 2004;53:879-884.

5. Cha JM, Kozarek RA, La Selva D, et al. Findings of diagnostic colonoscopy in young adults versus findings of screening colonoscopy in patients aged 50 to 54 years: a comparative study stratified by symptom category. Gastrointest Endosc 2015;82:138-145.

6. Lewis JD, Shih CE, Blecker D. Endoscopy for hematochezia in patients under 50 years of age. Dig Dis Sci 2001;46:2660-2665.

7. Nikpour S, Ali Asgari A. Colonoscopic evaluation of minimal rectal bleeding in average-risk patients for colorectal cancer. World J Gastroenterol 2008; 14:6536-6540.

8. Carlo P, Paolo RF, Carmelo B, et al. Colonoscopic evaluation of hemato- chezia in low and average risk patients for colorectal cancer: a prospective study. World J Gastroenterol 2006;12:7304-7308.

9. Acosta JA, Fournier TK, Knutson CO, Ragland JJ. Colonoscopic evaluation of rectal bleeding in young adults. Am Surg 1994;60:903-906.

10. Spinzi G, Fante MD, Masci E, et al. Lack of colonic neoplastic lesions in patients under $50 \mathrm{yr}$ of age with hematochezia: a multicenter prospective study. Am J Gastroenterol 2007;102:2011-2015.

11. Khalid AB, Majid S, Salih M, Hashmat F, Jafri W. Is full colonoscopic examination necessary in young patients with fresh bleeding per rectum? Endoscopy 2011;43:692-696.

12. Siegel RL, Jemal A, Ward EM. Increase in incidence of colorectal cancer among young men and women in the United States. Cancer Epidemiol Biomarkers Prev 2009;18:1695-1698.

13. Meyer JE, Narang T, Schnoll-Sussman FH, Pochapin MB, Christos PJ, Sherr DL. Increasing incidence of rectal cancer in patients aged younger than 40 years: an analysis of the surveillance, epidemiology, and end results database. Cancer 2010;116:4354-4359.

14. Robertson R, Campbell C, Weller DP, et al. Predicting colorectal cancer risk in patients with rectal bleeding. Br J Gen Pract 2006;56:763-767.

15. National Registry of Diseases Office (NRDO). Singapore cancer registry. Annual registry report. Trends in cancer incidence in Singapore 2010-2014 [Internet]. Singapore: Health Promotion Board; c2015 [cited 2020 Feb 2]. Available from: https://www.nrdo.gov.sg/docs/librariesprovider3/default-document-library/cancer-trends-report-2010---2014_ web.pdf?sfvrsn $=0 \% 20$ found $\% 20$ the $\% 20$ reference.

16. Chan PW, Ngu JH, Poh Z, Soetikno R. Colorectal cancer screening. Singapore Med J 2017;58:24-28.

17. Pitluk H, Poticha SM. Carcinoma of the colon and rectum in patients less than 40 years of age. Surg Gynecol Obstet 1983;157:335-337.

18. Nguyen SP, Bent S, Chen YH, Terdiman JP. Gender as a risk factor for advanced neoplasia and colorectal cancer: a systematic review and meta-analysis. Clin Gastroenterol Hepatol 2009;7:676-681.e1-e3. 